\title{
Microbiomes of different ages in Rendzic Leptosols in the Crimean Peninsula
}

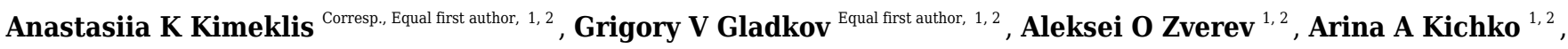 \\ Evgeny E Andronov $^{2,3,4}$, Elena I Ergina ${ }^{5}$, Igor V Kostenko ${ }^{6}$, Evgeny V Abakumov ${ }^{1}$ \\ ${ }^{1}$ Applied Ecology, St. Petersburg State University, Saint-Petersburg, Russia \\ 2 Laboratory of microbiological monitoring and bioremediation of soils, All-Russian Research Institute for Agricultural Microbiology, Pushkin, Russia \\ 3 Genetics and Biotechnology, St. Petersburg State University, Saint-Petersburg, Russia \\ 4 V.V. Dokuchaev Soil Science Institute, Moscow, Russia \\ 5 V.I. Vernadsky Crimean Federal University, Simferopol, Russia \\ 6 Nikitsky Botanical Garden - National Scientific Center, Yalta, Russia \\ Corresponding Author: Anastasiia K Kimeklis \\ Email address: kimeklis@gmail.com
}

Rendzic Leptosols are intrazonal soils formed on limestone bedrock. The specialty of these soils is that parent rock material is more influential in shaping soil characteristics than zonal factors such as climate, especially during soil formation. Unlike fast evolving Podzols due to their leaching regime, Leptosols do not undergo rapid development due to the nature of the limestone. Little is known how microbiome reflects this process, so we assessed microbiome composition of Rendzic Leptosols of different ages, arising from disruption and subsequent reclamation. The mountains and foothills that cover much of the Crimean Peninsula are ideal for this type of study, as the soils were formed on limestone and have been subjected to anthropogenic impacts through much of human history. Microbiomes of four soil sites forming a chronosequence, including different soil horizons, were studied using sequencing of 16S rRNA gene libraries and quantitative PCR. Dominant phyla for all soil sites were Actinobacteria, Proteobacteria, Acidobacteria, Bacteroidetes, Thaumarchaeota, Planctomycetes, Verrucomicrobia and Firmicutes. Alpha diversity was similar across sites and tended to be higher in topsoil. Beta diversity showed that microbiomes diverged according to the soil site and the soil horizon. The oldest and the youngest soils had the most similar microbiomes, which could have been caused by their geographic proximity. Oligotrophic bacteria from Chitinophagaceae,

Blastocatellaceae and Rubrobacteriaceae dominated the microbiome of these soils. The microbiome of 700-year old soil was the most diverse. This soil was from the only study location with topsoil formed by plant litter, which provided additional nutrients and could have been the driving force of this differentiation. Consistent with this assumption, this soil was abundant in copiotrophic bacteria from Proteobacteria and Actinobacteria phyla. The 
microbiome of 50-year old Leptosol was more similar to the microbiome of benchmark soil than the microbiome of 700-year old soil, especially by weighted metrics. CCA analysis, in combination with PERMANOVA, linked differences in microbiomes to the joint change of all soil chemical parameters between soil horizons. Local factors, such as parent material and plant litter, more strongly influenced the microbiome composition in Rendzic Leptosols than soil age. 
1 Microbiomes of different ages in Rendzic Leptosols in 2 the Crimean Peninsula

3

4 Anastasiia K. Kimeklis ${ }^{1,2}$, Grigory V. Gladkov ${ }^{1,2}$, Aleksei O. Zverev ${ }^{1,2}$, Arina A. Kichko ${ }^{1,2}$,

5 Evgeny E. Andronov ${ }^{2,3,4}$, Elena I. Ergina ${ }^{5}$, Igor V. Kostenko ${ }^{6}$, Evgeny V. Abakumov ${ }^{1}$

$7 \quad{ }^{1}$ Applied Ecology, St. Petersburg State University, Saint-Petersburg, Russia

8 2Laboratory of microbiological monitoring and bioremediation of soils, All-Russian Research

9 Institute for Agricultural Microbiology, Pushkin, Russia

$10{ }^{3}$ Genetics and Biotechnology, St. Petersburg State University, Saint-Petersburg, Russia

$11{ }^{4}$ V.V. Dokuchaev Soil Science Institute, Moscow, Russia

$12{ }^{5}$ V.I. Vernadsky Crimean Federal University, Simferopol, Russia

$13{ }^{6}$ Nikitsky Botanical Garden - National Scientific Center, Yalta, Russia

15 Corresponding Author:

16 Anastasiia Kimeklis ${ }^{1,2}$

17 Email address: kimeklis@gmail.com 
18

19

20

21

22

23

24

25

26

27

28

29

30

31

32

33

34

35

36

37

38

39

40

41

42

43

44

45

46

47

48

49

50

51

52

53

54

55

56

57

\section{Abstract}

Rendzic Leptosols are intrazonal soils formed on limestone bedrock. The specialty of these soils is that parent rock material is more influential in shaping soil characteristics than zonal factors such as climate, especially during soil formation. Unlike fast evolving Podzols due to their leaching regime, Leptosols do not undergo rapid development due to the nature of the limestone. Little is known how microbiome reflects this process, so we assessed microbiome composition of Rendzic Leptosols of different ages, arising from disruption and subsequent reclamation. The mountains and foothills that cover much of the Crimean Peninsula are ideal for this type of study, as the soils were formed on limestone and have been subjected to anthropogenic impacts through much of human history. Microbiomes of four soil sites forming a chronosequence, including different soil horizons, were studied using sequencing of 16S rRNA gene libraries and quantitative PCR. Dominant phyla for all soil sites were Actinobacteria, Proteobacteria, Acidobacteria, Bacteroidetes, Thaumarchaeota, Planctomycetes, Verrucomicrobia and Firmicutes. Alpha diversity was similar across sites and tended to be higher in topsoil. Beta diversity showed that microbiomes diverged according to the soil site and the soil horizon. The oldest and the youngest soils had the most similar microbiomes, which could have been caused by their geographic proximity. Oligotrophic bacteria from Chitinophagaceae, Blastocatellaceae and Rubrobacteriaceae dominated the microbiome of these soils. The microbiome of 700-yearold soil was the most diverse. This soil was from the only study location with topsoil formed by plant litter, which provided additional nutrients and could have been the driving force of this differentiation. Consistent with this assumption, this soil was abundant in copiotrophic bacteria from Proteobacteria and Actinobacteria phyla. The microbiome of 50-year-old Leptosol was more similar to the microbiome of benchmark soil than the microbiome of 700-year-old soil, especially by weighted metrics. CCA analysis, in combination with PERMANOVA, linked differences in microbiomes to the joint change of all soil chemical parameters between soil horizons. Local factors, such as parent material and plant litter, more strongly influenced the microbiome composition in Rendzic Leptosols than soil age.

\section{Introduction}

The soil microbiome is an essential part of the soil structure (Attwood et al., 2019; Dubey et al., 2019; Wei et al., 2019). Understanding soil microbiome composition and function help reveal key processes of soil formation and implementation of vital ecosystem services (Doula \& Sarris, 2016; Saleem, Hu \& Jousset, 2019). The process of soil formation, or pedogenesis, depends on multiple factors, including climate, vegetation, topography, and parent material (Dokuchaev, 1883). The type of the parent material determines the rate of soil profile differentiation (Gagarina, Khantulev \& Chikhikova, 1981; Gagarina, 1996), thus affecting microbiome formation. Hard limestone rock as a parent material promotes the formation of weakly developed soils, called Rendzic Leptosols (Homolák et al., 2017). Such soils are considered to be intrazonal, because local factors, such as parent material, affect their characteristics much more than climate (Perkins, 1951). Limed soils have higher microbial biomass than unlimed (Bakina, 
58

59

60

61

62

63

64

65

66

67

68

69

70

71

72

73

74

75

76

77

78

79

80

81

82

83

84

85

86

87

88

89

90

91

92

93

94

95

96

97

2014; Narendrula-Kotha \& Nkongolo, 2017). Soil liming also affects the stability of humic acids, reducing labile humic content (Bakina, 2014). However, it does not affect organic matter content. Actinobacteria and Acidobacteria are more prevalent in more acidic soils with high carbon content and leaching of nitrates, while in less acidic soils with lower carbon content, nitrogen is accumulated, encouraging the growth of Proteobacteria (Barta et al., 2017). According to Targulian, every disruption of the soil surface sets soil formation process, or pedogenesis, to zero (Targulian and Bronnikova, 2019). Thus, different stages of the pedogenesis can be approached by studying chronosequences, which are series of soils, formed at different times under similar climatic and biogenic conditions (Emmer, 1995; Mokma, YliHalla \& Lindqvist, 2004; Cerli et al., 2008; Abakumov et al., 2010). Soil chronosequences form at the terraces of reservoirs, on the dunes, under the barrows and the quarry dumps (Gennadiev, 1990). Series of coastal bars in Lake Ladoga (Russia), formed by a gradual lowering of the water level showed that in the process of pedogenesis, bulk soil is divided into horizons, and microbiome composition is divided according to these horizons (Ivanova et al., 2020). Other objects used to evaluate pedogenesis are soils on reclaimed mining heaps (Anderson, 1977; Frouz, 2014; Sokolov et al., 2015). Initially, microbiomes of young soils are abundant in Chloroflexi and Cyanobacteria, photosynthetic bacteria which can survive with limited number of nutrients (Gladkov et al., 2019). Quite rapidly after development, however, copiotrophic bacteria populate these soils (Kimeklis et al., 2020).

The Crimean Peninsula contains numerous diverse climatic zones, ranging from the dry steppes in the north to the forest-steppe and forest in the mountains and subtropics on the southern coast (Lisetskii \& Ergina, 2010). Origins, texture classes and chemical composition of parent material also have variation in different parts of the peninsula. Intensive human activity over thousands of years on the limestone formed differently aged soils on the calcareous parent material in this area (Dragan, 2005; Stolba, Lisetskii \& Marinina, 2015). Moreover, open cast mining is the most severe type of current exogenic transformation of environments in the Crimean Peninsula. These parent materials are the most problematic in terms of ecosystem reclamation and restoration.

Parent material alongside with topography constitute geogenic conditions, which determine the speed of soil formation (pedogenesis rate) (Brevik and Lazari, 2014). The role of parent materials in soils formation is directly connected with degree of consolidation and mineralogical composition, while the topography seriously effects the insolation rate and the degree of water retention capacity in elevated forms of relief (Targulian and Krasilnikov, 2007). In this context, the soils of the first two ridges of Crimea mountains represent well drained calcaric polypedones covered with Leptosols (or Lithosols) with weak profiles, not essentially differentiated in vertical scale. Thus, the chronosequences of soils in conditions of Crimea are less explored in sense of soil profiles developments rate in comparison with soil series of humid climate, located on acid or neutral parent materials. While in taiga zone 100-200 years is enough for development of embryonic soil profile, in case of Crimean forest-steppes of the mountain ridges the zonal soil profile normally forms 4-7 times longer. Here we address the subject of microbiome composition in soils of different ages in multiple Rendzic Leptosols horizons of the Crimean forest-steppe 
zone. The subject of this study were four territories, formed under the same climatic conditions and from the same parent rock material, composing a chronosequence. Their age ranged from native soil to 700, 70 and 50 years, the range resulting from different anthropogenic impacts (Lisetskii \& Ergina, 2010). The aim of this study was to investigate microbiome diversity, including bacteria and archaea, of the soil chronosequence on derivatives of limestones in different stages of ecosystem development, using quantitative PCR and high-throughput sequencing of $16 \mathrm{~S}$ rRNA gene libraries. Investigation of these chronosequences may provide new information about the rates of soil formation during different stages of ecogenesis on the surface of limestones.

\section{Materials \& Methods}

Study sites and sample collection

All sites are represented by the Rendzic Leptosols located in the first and second mountain ridges in the forest-steppe zone of Crimean Peninsula. The climate of this zone is more humid than in northern part of the Peninsula. The annual precipitation rate is about $380-500 \mathrm{~mm}$ per year while the evaporation rate is $750-850 \mathrm{~mm}$. Annual average temperature is $+20-22 \mathrm{C}^{\circ}$. The depth of soil freezing is no more than $20 \mathrm{~cm}$. Overall, the climate of the investigated area is very close to Mediterranean one. The heights of the relief range between 300-750 m, while topography of the territory is strongly affected by composition and texture of limestones. Limestones are presented by sedimentary rocks strongly affected by karst and denudation processes. Normally, limestone surface was not covered by any other quaternary sediment and this fact provides the possibility for the soil to be formed according to the model of primary soil formation. Thus, all sites are comparable in terms of pedogenesis conditions. Meanwhile, all sites comprise different chronosequence stages, which originated from anthropogenic exploitation of mines for construction and other processes in different historical periods. Age of each chronosequence stage was confirmed by historical documents (Lisetskii \& Ergina, 2010). Benchmark site K3 was presented by native brown soil, formed around the Holocene. Site K1 with the oldest anthropogenic impact is located in the 700-year-old territory of medieval fortress city EskiKermen, which was destroyed at the end of the 14th century. Near K3 site is site K2, representing 75-year-old WWII trenches in Holmovka village. Site K6 is an overgrown quarry in the north of Belogorsky district with gravel-sandy textured carbonate containing heaps, which was reclaimed approximately 50 years ago. All soil profiles are Leptosols of various thicknesses; the thickness of the humus horizon and the degree of weathering of the fine earth soil increased with age. Samples were collected in the summer of 2018. They were taken from each soil profile for each horizon in 5 replicates. Quantity of horizons differed through sites due to differences in soil profiles: $\mathrm{O}, \mathrm{AY}$ and $\mathrm{C}$ from the $\mathrm{K} 1, \mathrm{AY}$ and $\mathrm{C}$ from $\mathrm{K} 2$ and $\mathrm{K} 3$, AY from $\mathrm{K} 6$. The coordinates of the K1 site were $44^{\circ} 36.554 \mathrm{~N}, 33^{\circ} 44.376 \mathrm{E}$; K2 and K3 sites $44^{\circ} 39.171 \mathrm{~N}$, $33^{\circ} 44.968 \mathrm{E}$; K6 site $45^{\circ} 07.644 \mathrm{~N}, 34^{\circ} 35.537 \mathrm{E}$ (Fig. 1). All soils samples were acquired with the approval of V.I. Vernadsky Crimean Federal University. 
137 Soils for routine analyses were ground and passed through a $2 \mathrm{~mm}$ sieve; the large root debris 138 was removed manually. The main agrochemical parameters were measured: $\mathrm{P}_{2} \mathrm{O}_{5}$ and $\mathrm{K}_{2} \mathrm{O}$ by 139 the Machigin method (GOST 26205-91, 1991), pH (GOST 26213-91, 1991) and total nitrogen 140 (GOST 26107-84, 1984). Total organic carbon (TOC) was determined using a CHN analyser 141 (Leco CHN-628) in Research Park of St Petersburg State University.

142

DNA isolation, real-time and $16 \mathrm{~S} r \mathrm{DNA}$ library preparation

144 For the microbiome analysis, five replicate soil samples were collected from each horizon from 145 each site (40 total samples). From each sample, total DNA was isolated from 0.5 gram of soil 146 using the NucleoSpin ${ }^{\circledR}$ Soil Kit (Macherey-Nagel GmbH \& Co. KG, Germany) using a combination of SL1+SX buffers, recommended for soils with low organic content (Lazarevic et al., 2013). Samples were mechanically disintegrated using a Precellys 24 homogeniser (Bertin Technologies, France). The quality of isolation was tested by gel electrophoresis in $1 \%$ agarose gel $(0.5 \times$ TAE buffer). DNA concentrations were measured at $260 \mathrm{~nm}$ using SPECTROstar Nano (BMG LABTECH, Ortenberg, Germany). The final DNA concentration was, on average,

\section{$50 \mathrm{ng} / \mu \mathrm{L}$.}

153

Quantitative PCR (qPCR) was conducted for two groups of organisms: bacteria and archaea as

154 previously described in Gladkov et al., 2019. Each sample, including standards, was analysed in triplicate. The mean values with standard errors were calculated for replicates of both PCR and DNA samples. After processing, the results were expressed as the common logarithm of the number of ribosomal operons per $1 \mathrm{~g}$ soil. Construction and sequencing of the 16S rRNA amplicon libraries was conducted using an Illumina MiSeq (Illumina, Inc, USA) at the Centre for Genomic Technologies, Proteomics and Cell Biology (ARRIAM, Russia) as described in Gladkov et al., 2019.

161

\section{Data processing}

Amplicon libraries of the 16S rRNA gene were processed using packages in the $\mathrm{R}$ ( $R$ core team, 2018) and QIIME2 (Bolyen et al., 2019) software environments. Rstudio (RStudio Team, 2016) was used as the development environment for R. Trimming, combining sequences into phylotypes and subsequent processing was performed through dada2 package (Nearing et al., 2018), which provides more reproducible and accurate results due to the use of denoising algorithms rather than clustering of phylotypes, in contrast to more classical approaches (Callahan et al., 2016). The taxonomic affiliation of phylotypes was determined using the RDP classifier (Wang et al., 2007) based on Silva 132 (Quast et al., 2013). The phylogenetic tree was built in the QIIME2 software environment using the SEPP package (Janssen et al., 2018). For some analyses, data were normalised by phyloseq (McMurdie \& Holmes, 2013) using the rarefaction algorithm according to the sample with the smallest number of readings, and were stabilised by variation through the Deseq2 package (Love, Huber \& Anders, 2014) to compare the relative abundances of phylotypes in the samples. For the analysis of alpha diversity, the following indices were used: the observed OTU, Shannon (Shannon \& Weaver, 1949), the 
177 inverse Simpson (Simpson, 1949) and Faith phylogenetic diversity (Faith, 1992). Significance of

178

179

180

181

182

183

184

185

186

187

188

189

190

191

192

193

194

195

196

197

198

199

200

201

202

203

204

205

206

207

208

209

210

211

212

213

214

215

mean differences was calculated by the Mann-Whitney test (Mann \& Whitney, 1947). For the analysis of beta diversity, communities were compared using the construction of their dissimilarity matrix using the weighted UniFrac, unweighted UniFrac (Lozupone \& Knight, 2005) and Bray-Curtis algorithms (Bray \& Curtis, 1957). When visualising the data on beta diversity, the dimensions of the dissimilarity matrices were reduced using NMDS (Kruskal, 1964). The significance of sample separation in the analysis of beta diversity was assessed by PERMANOVA (Anderson, 2017) in the form of the adonis2 test as part of the vegan package (Oksanen et al., 2019). To analyse the variation of beta diversity by soil chemical parameters, the constrained correspondence analysis (CCA) was used (ter Braak, 1986; Palmer, 1993; McCune, 1997). To assess the possible multicollinearity of the CCA model, generalised variance-inflation factors for linear models were used (Fox \& Monette, 1992; Fox, 1997). The CCA function and reliability analyses of the model were conducted using the vegan package. To estimate the significance of differences between phylotypes, previously normalised data were processed using the Wald test, with a Benjamin-Hotchberg false discovery rate (FDR) correction in the DEseq2 package (Benjamini \& Hochberg, 1995).

The R packages phyloseq, ggpubr (Kassambara, 2019), picante (Kembel, 2010), ggforce (Pedersen, 2019), tidyverse (Wickham et al., 2019), ggtree (Yu et al., 2018), ampvis2 (Andersen et al., 2018) were used for post-processing and visualisation of the obtained data.

\section{Results}

\section{Soil chemical parameters}

All soils demonstrated alkalinity (from 8.2 to 7.6 ) and a high content of carbonates (4.8-45.6\%), which is typical of Rendzic Leptosols. For the $\mathrm{K} 1$ and $\mathrm{K} 2$ sites, $\mathrm{pH}$ and carbonates decreased towards the upper horizons (topsoil), due to leaching processes. Carbonate content in the $\mathrm{C}$ horizon at the K3 site (4.8\%) was lower than in the AY horizon (28.57\%) because most of the carbonates are immobilised in the skeleton of the soil. K1 was the only site with an O horizon in a soil profile; this type of horizon is formed by herbage without grazing. Therefore, it had the highest amount of total organic carbon (TOC) and nitrogen content. Leptosol in site K6 was of a slightly alkaline $\mathrm{pH}(7.7)$ and had significant reserves of potassium $(1110 \mathrm{mg} / \mathrm{kg})$ and phosphorus $(285 \mathrm{mg} / \mathrm{kg})$, caused by the use of the surrounding territory by the locals of the Vishennoe village to dispose of household waste (Table 1).

\section{Quantitative PCR}

Quantitative PCR showed that the number of bacteria ribosomal operons per $1 \mathrm{~g}$ of soil was high across all sites and horizons (Fig. 2). The archaea operon count varied by horizon, but for K1 and $\mathrm{K} 2$ sites, it increased towards the lower horizons.

Initial quality control and phyla composition

Peer) reviewing PDF | (2020:07:50777:1:1:NEW 11 Dec 2020) 
216 After initial processing of 40 amplicon libraries of 16S rRNA genes, three samples were

217 excluded from the subsequent analysis due to their poor agreement with a rarefaction curve (Fig.

218 S1). All data is available at SRA database (SRA Toolkit Development Team) under BioProject ID

219 PRJNA645404. The final output of the 16S rRNA gene library sequencing included 37 samples

220 with a total of 1145454 reads. The minimum number of detected reads were 13925, maximum -

22141384 and average read number - 30958.22. A total of 12311 OTUs were observed: 11705

222 (95\%) OTUs were assigned to the kingdom level, 11026 (89.56\%) - phylum level, 10814

$223(87.84 \%)$ - class level, $9406(76.4 \%)$ - order level, $7800(63.36 \%)$ - family level, $3993(32.43 \%)$

224 - genus level and 277 (2.25\%) - species level.

225 The most abundant phyla across all samples were Actinobacteria, Proteobacteria, Acidobacteria,

226 Bacteroidetes, Thaumarchaeota, Planctomycetes, Verrucomicrobia, Firmicutes and Chloroflexi

227 (Fig. 3). Site K1 was most clearly distinct from other sites by phyla composition, the most drastic

228 difference being the almost complete absence of Firmicutes representatives. Some phyla

229 demonstrated shifts in abundance correlating with the soil horizon: Bacteroidetes and

230 Proteobacteria were more abundant in topsoil horizons, while Thaumarchaeota, Acidobacteria

231 and Verrucomicrobia were more abundant in lower horizons. This observation is consistent with

232 qPCR data. Bacterial ribosomal count was approximately equal between horizons probably

233 because different bacteria groups shift their abundance in opposing directions through the

234 horizons; and Thaumarchaeota, being the dominant archaeal phyla, was responsible for total

235 archaea increase in lower horizons.

236 On a family level, the most abundant taxa were Nitrososphaeraceae (Thaumarchaeota),

237 Chitinophagaceae and Microscillaceae (Bacteroidetes), 67-14 and Micromonosporaceae

238 (Actinobacteria), Xanthobacteriaceae and Burkhorderiaceae (Proteobacteria) and

239 Pyrinomonadaceae (Acidobacteria) (Fig. S2). In K1 site samples, phylotypes from

240 Rubrobacteriaceae and Bacillales were less abundant than in other samples and

241 Solirubrobacteriaceae were more abundant. Sphingomonadaceae were more abundant in topsoil.

242 Xiphinematobacteriaceae were more abundant in deeper AC and C horizons.

243

244 Alpha diversity

245 All alpha diversity indices revealed the higher horizons demonstrated a tendency towards higher 246 diversity (Fig. 4). The maximum observed number of OTUs was detected in K1-O and K6-AY, 247 and the minimum in $\mathrm{K} 3-\mathrm{C}$. In the $\mathrm{K} 1$ and $\mathrm{K} 3$ sites, observed OTU significantly decreased toward 248 the lower horizon. AY horizons across all sites had comparable OTU numbers. The Faith index, 249 which demonstrates phylogenetic distance (PD), was evenly distributed between samples, with 250 no apparent maximum or minimum. However, it also showed separation of samples by horizon. 251 The Shannon index evaluates diversity, particularly evenness, with respect to minor taxa, while 252 the inverted Simpson index takes into account more abundant taxa. Using the Shannon index, 253 K1-O was similar in diversity to K6-AY but was different according to the inverted Simpson 254 index. In general, the inverted Simpson index shows that K1-O was most diverse, while samples 255 from K2, K3 and K6 sites show significant, but slight, separation from each other. Furthermore, 
256

257

258

259

260

261

262

263

264

265

266

267

268

269

270

271

272

273

274

275

276

277

278

279

280

281

282

283

284

285

286

287

288

289

290

291

292

293

294

K6-AY was closer in diversity to K1-O and K1-AY than K2 and K3 sites by the Shannon index. In summary, all diversity indices to varying extents show a separation of samples by soil horizon, alongside with secluded position of samples from K1 and K6 sites.

\section{Beta-diversity and CCA}

Beta diversity demonstrated two clear trends, coinciding with the axes (Fig. 5). Along the "Y" axis samples tended to line up according to the soil horizons. Along the "X" axis, samples were divided into "site" groups: Bray-Curtis and UniFrac algorithms showed that one group included all samples from the K1 site, the second group included the only sample from K6 site and the third, all samples from both K2 and K3 sites. According to the weighted UniFrac algorithm, samples from the K6 site group together with samples from K2 and K3 sites, which is consistent with results of the inverted Simpson index.

PERMANOVA showed that soil horizon had the maximum coefficient of determination (Table 2). The next factor was the sampling site. All the soil agrochemical parameters, except for carbonates $\left(\mathrm{C}_{\mathrm{carb}}\right)$, demonstrated similar significance, but with low coefficient of determination values. PERMANOVA nested by horizon showed that all agrochemical factors, including $\mathrm{C}_{\text {carb}}$, became significant (Table $\mathrm{S} 1$ ). .

The model of CCA performed for agrochemical factors is statistically significant, although it demonstrated that these factors could not explain the discrepancy between sample sites (Fig. 6). However, they explained soil stratification into horizons. The test on the variance inflation factor showed all agrochemical factors, including $\mathrm{pH}$, demonstrated multicollinearity. A combination of CCA and PERMANOVA confirm that variability between soil horizons was associated with agrochemical factors.

\section{K1/K3 phylotype comparisons}

Previous analyses concluded that microbiomes across all sites separate by soil horizon, but also that microbiomes from the $\mathrm{K} 1$ site are more distinct from other sites. To assess more precise differences in microbiome composition between sites, we visualised significant shifts of phylotype abundance in $\mathrm{AY}$ and $\mathrm{AC} / \mathrm{C}$ horizons between the $\mathrm{K} 1$ and $\mathrm{K} 3$ sites (Fig. 7). Despite the major trend of microbiome differences between soil horizons, our analysis shows that the reactive component of the soil microbiome shifted together in both soil horizons between different soil sites. Firmicutes, in particular Planococcaceae and B. longiquaestium, increased in K3; Actinobacteria (Solirubrobacter, Gaiella, 67-14, Microlunatus, Ilumatobacteraceae) mostly increased in K1, except for Rubrobacter; Proteobacteria (Deltaproteobacteria, Bradyrhizobium, Xanthobacteriaceae, Rhodoplanes, Pedomicrobium, Reyranella, Geminicoccaceae, Burkhordeliaceae, MND1, Steroidobacter uvarum) were more abundant in K1. Representatives of Verrucomicrobia (Xiphinematobacter, Udaeobacter), Thaumarchaeota (Nitrososphaeraceae) and Acidobacteria (NA, RB41) varied in both K1 and K3 sites. Variation of Thaumarchaeota in both $\mathrm{K} 1$ and $\mathrm{K} 3$, the growth of which depends on nitrogen content, supports the earlier 
295 conclusions that nitrogen content doesn't explain site differences. However, the K1 site was

296 abundant in Actinobacteria and Proteobacteria related phylotypes.

297

298

299

300

301

302

303

304

305

306

307

308

309

310

311

312

313

314

315

316

317

318

319

320

321

322

323

324

325

326

327

328

329

330

331

332

333

\section{K2/K3 phylotype comparisons}

Microbiomes of the AY and C horizons from two sites in Holmovka village (K2 and K3) were the closest to each other on the beta diversity plots. These data are supported by log2FoldChange values for the 30 of the most abundant phylotypes of both horizons between sites (Table S2). Almost half of these phylotype changes were not significant. The greatest differences in topsoil (more than 10 times more at K3-AY than K2-AY) were for Seq13 (Oxyphotobacteria from Cyanobacteria), Seq101 and Seq136 (Planococcaceae from Firmicutes), Seq322

(Chitinophagaceae from Bacteroidetes) and Seq339 (Romboutsia from Firmicutes). For the deeper horizon, the only phylotype matching these conditions was Seq445 (Adhaeribacter from Bacteroidetes).

\section{K6/K3/K1 phylotype comparisons}

To assess the specificity of microbiome composition of the Leptosol at the K6 site, similar to K2 and $\mathrm{K} 3$ sites, we estimated shifts in abundance by calculating log2FoldChange values for 30 phylotypes for K6-AY/K3-AY and K6-AY/K1-AY pairs (Table S3). All log2FoldChange values were significant, except for the only phylotype in the K6-AY/K3-AY pair. Eleven phylotypes appeared in both pairs of comparisons, and most of them were more abundant in K6-AY: Seq20 and Seq161 (Nitrososphaeraceae from Thaumarchaeota), Seq11 and Seq119 (RB41 from Acidobacteria), Seq94 (Subgroup 6 from Acidobacteria), Seq53 (Chitinophagaceae from Bacteroidetes) and Seq165 (Oxyphotobacteria from Cyanobacteria). However, a lot of other phylotypes were underrepresented in K6 compared to the other two sites. In comparison with K3-AY, the K6-AY site contained more than 10 times fewer of the following phylotypes: Seq13 (Oxyphotobacteria from Cyanobacteria), Seq5 (Candidatus_Xiphinematobacter from Verrucomicrobia), Seq37 (Chitinophagaceae from Bacteroidetes), Seq101 and Seq136 (Planococcaceae from Firmicutes), Seq60 (Aridibacter famidurans from Acidobacteria) and Seq34 (Thermoleophilia from Actinobacteria). Compared to K1-AY, the K6-AY site contained more than 10 times less of the following phylotypes: Seq6 and Seq36 (Thermoleophilia from Actinobacteria), Seq33 (Nitrososphaeraceae from Thaumarchaeota), Seq25 (Microlunatus from Actinobacteria) and Seq49 (MND1 from Proteobacteria). K6-AY was more abundant than K1AY by Seq3 (Bacillus longiquaesitum from Firmicutes) and Seq32 (Candidatus_Nitrososphaera from Thaumarchaeota). These differences show that topsoil microbiomes of all sites were composed of similar major phylotypes, including both oligo- and copiotrophic taxa, which shifted between sites regardless of their trophic group. These data are consistent with the observation that the changing soil chemical parameters have not explained the beta diversity observed between sites.

Peer) reviewing PDF | (2020:07:50777:1:1:NEW 11 Dec 2020) 


\section{Discussion}

335 In our comparisons we focused on differences between Leptosols of various ages. Microbiomes 336 of all these soil samples shared some similar taxa at the phylotype level, but most of them shifted

337

338

339

340

341

342

343

344

345

346

347

348

349

350

351

352

353

354

355

356

357

358

359

360

361

362

363

364

365

366

367

368

369

370

371

372

373 their abundance according to the soil site or soil horizon. One of the major groups of phylotypes was composed of archaea from the Nitrososphaeraceae family in the Thaumarchaeota phylum. These archaea are capable of ammonia oxidation and are considered to play a significant role in nitrogen cycling in the soil, especially in an arid and low-nutrition environment (Pester, Schleper \& Wagner, 2011; Kimble et al., 2018; Nelkner et al., 2019). Consistent with this, we found Nitrososphaeraceae more frequently inhabited deep soil horizons that were poor in nutrients across all studied sites. Moreover, it was the least frequent in the O horizon at the K1 site, which was the richest in total nitrogen. Notably, microbiomes from each site had dominant Nitrososphaeraceae of different phylotypes, e.g. Seq1 was more abundant in K3, Seq2 in K1 and Seq16 in K6. However, this segregation of phylotypes did not affect the overall dominance of Nitrososphaeraceae across horizons at different sites (Fig. S2). It should be noted that high amount of archaeal phylotypes goes in concordance with high amount of archaea in samples shown by qPCR.

The second largest family across all sites was Chitinophagaceae from Bacteroidetes. Bacteroidetes are oligotrophs (Fierer, Bradford \& Jackson, 2007). Representatives within this phylum, Chitinophagaceae in particular, are essential for carbon decomposition, especially in sandy, loamy soils (Ho et al., 2017; Fernandes et al., 2018). Consistent with this data, Bacteroidetes were more abundant in the lower nutrient soils of K2 and K3 sites.

The representatives of the phylum Acidobacteria are sensitive to soil acidity, macro- and micronutrients, capable of utilising nitrite and playing a role in cellulose decomposition (Kielak et al., 2016). They are also considered oligotrophs (Fierer et al., 2012). This phylum is one of the major ones in our dataset, but in comparison with previous data on soil microbiome composition (Janssen, 2006; Jones et al., 2009), its relatable abundance was quite low. At the first sight this is consistent with the fact that its representatives are usually linked to acidic environments (Belova et al., 2018; Ivanova et al., 2020), while soils from our dataset are alkaline. However, acidobacteria are gram negative and very sensitive to drought (Barnard et al., 2013; Chodak et al., 2015; Zhou et al., 2016), so another explanation of low relative abundance of acidobacteria, in our dataset can be connected to the season of sample collection (summer) or microbiome alterations during sample transportation. For instance, representatives of Pyrinomonadaceae family, present in all samples, live in arid conditions and be able to utilise a limited spectrum of carbon and energy sources (Wüst et al., 2016). Sites K2 and K3 were abundant in Blastocatellaceae, whose members have been isolated from African Savannah soils with low nutrient contents and were reported to be able to degrade complex carbon compounds (Huber et al., 2017).

In contrast to Bacteroidetes and Acidobacteria, Proteobacteria (especially Alphaproteobacteria) are considered to be mostly copiotrophs (Campbell et al., 2010; Ramirez et al., 2010; Fierer et al., 2012). As expected, Proteobacteria members were the most abundant in the most nutrient- 
374 rich soil of the K1 site. Xanthobacteraceae members, dominant in this dataset, demonstrate a

375 variety of metabolic strategies, including aerobic chemoheterotrophy, facultative

376 chemolithoautotrophy and nitrogen fixation (Kappler \& Nouwens, 2013; Oren, 2014). Some also

377 live in association with leguminous plants. Sphingomonadaceae are commonly isolated from the

378 soil and rhizosphere in particular (Glaeser \& Kämpfer, 2014). They are reported to be a possible

379 tool of bioremediation due to their ability to degrade xenobiotic and recalcitrant (poly)aromatic

380 compounds.

381 Actinobacteria is one of the essential bacteria groups in the soil, significantly contributing to the

382 carbon cycle via their cellulolytic activity (Lewin et al., 2016), so they are usually associated

383 with the rhizosphere (Oberhofer et al., 2019). It is the most abundant phylum in our dataset, but

384 the least amount was detected in the Leptosol of the K6 site, which could mean that its

385 vegetation cover is not yet restored. The Actinobacteria phylum has been shown to include both

386 copio- and oligotrophic bacteria (Morrissey et al., 2016). Representatives of Rubrobacteriaceae

387 family, found in the K2 and K3 sites, have been reported to be oligotrophic. Some studies have

388 shown that these bacteria are also associated with lime wall paintings and painted statues of

389 Maijishan Grottoes (Schabereiter-Gurtner et al., 2001; Duan et al., 2017).

390 One of the most abundant phyla, determined using standard microbiological approaches, was

391 Firmicutes. However, sequencing of $16 \mathrm{~S}$ amplicon libraries showed that this is not always the

392 case (Janssen, 2006). Sometimes they comprise as low as 2\% of the total soil microbiome.

393 Meanwhile, spore-forming Bacillus was reported to be highly associated with the rhizosphere

394 (Toyota, 2015). Firmicutes, as gram-positive bacteria, are very resistant to many adverse

395 environmental conditions. They are also drought resistant. In our dataset Firmicutes is a minor

396 phylum, appearing mostly in the lower horizons of K2 and K3 sites, and the topsoil of the K6

397 site.

398 Another major phylotype from our dataset belonged to Xiphinematobacter, a nematode symbiont

399 (Brown et al., 2015). Interestingly, it was mostly found in AC and C horizons. It was likely an

400 amplification artefact since deeper horizons of soil had much less DNA.

401 Despite age differences, soil microbiomes from the K2 and K3 sites were the closest to each

402 other based on beta diversity. However, alpha diversity analysis revealed that the difference

403 between horizons in K3 was more pronounced than in K2. Probably, disturbance of soil in K2

404 did not affect the composition of the microbiome, but facilitated its penetration into lower soil

405 horizons. According to the results of weighted metrics (inverted Simpson index, weighted

406 unifrac algorithm), the microbiome from the Leptosol of the K6 site is grouped with samples

407 from the K2 and K3 sites. However, by the results of unweighted metrics (Shannon index, Bray-

408 Curtis and unweighted unifrac), the K6 site diverged from other sites, which could indicate that

409 the major microorganisms are similar in all these sites, but the K6 site has a significant portion of

410 a minor microbiome component. Soil from the K1 site was the most unique of all sites, likely

411 because it was under anthropogenic influence from the 6th to the 14th centuries (AD).

412 The structure of Rendzic Leptosol leads to a horizontal organisation, where the upper horizon

413 contains high amounts of humic compounds, and between it and the rock lies a fine-earth 
414 transition horizon. In these conditions, it is reasonable to assume that microbiome composition 415 would be significantly different between these horizons (Taş et al., 2018). Therefore, we tried to 416 link diversity of microbiome composition to several factors, such as site, horizon and different 417 agrochemical parameters. Beta-diversity showed that samples grouped according to both site and 418 soil horizon. Combination of CCA and PERMANOVA revealed that the most significant factor 419 for beta-diversity were the nutrients associated with the soil horizon. Although we could discern

420

421

422

423

424

425

426

427

428

429

430

431

432

433

434

435

436

437

438

439

440

441

442

443

444

445

446

447

448

449

450

451

452

453 that the difference between microbiomes of different soil horizons was linked with the changing of all soil agrochemical parameters, all these parameters, including $\mathrm{pH}$, shifted together, and it was impossible to identify the influence of any individual factor.

\section{Conclusions}

Here we focused on a microbiome composition of differently aged Rendzic Leptosols. As they are intrazonal, these Rendzic Leptosols soils are profoundly affected by their parent material and undergo very slow paedogenic process. Our research demonstrated that soil type on a limestone rock is the driving force behind microbiome shaping, without any apparent influence of its age. Overall, microbiomes from all sites were deficient in Acidobacteria due to the alkalinity or aridity of the environment. The benchmark soil was rich in oligotrophic bacteria

(Chitinophagaceae, Blastocatellaceae, Rubrobacteriaceae), able to decompose complex carbon sources. The youngest soil microbiome was the most similar to the benchmark, with only slight differences in microbiome diversity between horizons. Site K1 was the only one with topsoil, formed by plant litter. It introduced additional organic matter, thus promoting an increase in copiotrophic bacteria (Xanthobacteriaceae, representatives of Actinobacteria). Despite that, the major factor determining soil microbiome composition was the nutrients associated with the soil horizon, and our analysis showed that the reactive component of the soil microbiome shifted simultaneously in both soil horizons between different soil sites.

\section{References}

Abakumov E, Trubetskoj O, Demin D, Celi L, Cerli C, Trubetskaya O. 2010. Humic acid characteristics in podzol soil chronosequence. Chemistry and Ecology. 26:59-66. DOI: 10.1080/02757540.2010.497758

Andersen KS, Kirkegaard RH, Karst SM, Albertsen M. 2018. ampvis2: an R package to analyse and visualise 16S rRNA amplicon data. bioRxiv. DOI: 10.1101/299537.

Anderson DW. 1977. Early stages of soil formation on glacial till mine spoils in a semi-arid climate. Geoderma. 19:11-19. DOI: 10.1016/0016-7061(77)90010-6.

Anderson MJ. 2017. Permutational Multivariate Analysis of Variance (PERMANOVA). In Balakrishnan N, Colton T, Everitt B, Piegorsch W, Ruggeri F, Teugels JL, eds. Wiley StatsRef: Statistics Reference Online. DOI:10.1002/9781118445112.stat07841

Attwood GT, Wakelin SA, Leahy SC, Rowe S, Clarke S, Chapman DF, Muirhead R, Jacobs JME. 2019. Applications of the soil, plant and rumen microbiomes in pastoral agriculture. Frontiers in Nutrition. 6:107. DOI: 10.3389/fnut.2019.00107. 
454 Bakina LG, Chugunova MV, Zaitseva TB, Nebol'sina ZP. 2014. The effect of liming on the 455 complex of soil microorganisms and the humus status of a soddy-podzolic soil in a long-term 456 experiment. Eurasian Soil Science. 47: 110-118. DOI: 10.1134/S1064229314020021

457 Barnard R, Osborne C, Firestone M. 2013. Responses of soil bacterial and fungal communities to 458 extreme desiccation and rewetting. The ISME Journal. 7:2229-2241. DOI:

460 10.1038/ismej.2013.104

461

462

Bárta J, Tahovská K, Šantrůčková H, Oulehle F. 2017. Microbial communities with distinct denitrification potential in spruce and beech soils differing in nitrate leaching. Scientific Reports.

463

464

465

466

467

468

469

470

471

472

473

474

475

476

477

478

479

480

481

482

483

484

485

486

487

488

489

490

491

492

493 7:9738. DOI: 10.1038/s41598-017-08554-1.

Bates ST, Berg-Lyons D, Caporaso JG, Walters WA, Knight R, Fierer N. 2010. Examining the global distribution of dominant archaeal populations in soil. The ISME journal. 5:908-917. DOI:10.1038/ismej.2010.171.

Belova SE, Ravin NV, Pankratov TA, Rakitin AL, Ivanova AA, Beletsky AV, Mardanov AV, Sinninghe Damsté JS, Dedysh SN. 2018. Hydrolytic capabilities as a key to environmental success: chitinolytic and cellulolytic Acidobacteria from acidic sub-arctic soils and boreal peatlands. Frontiers in Microbiology. 19:2775. DOI: 10.3389/fmicb.2018.02775.

Benjamini Y, Hochberg Y. 1995. Controlling the false discovery rate: a practical and powerful approach to multiple testing. Journal of the Royal Statistical Society. Series B (Methodological). 57:289-300.

Bolyen E, Rideout JR, Dillon MR, Bokulich NA, Abnet CC, Al-Ghalith GA, Alexander H, Alm EJ, Arumugam M, Asnicar F, Bai Y, Bisanz JE, Bittinger K, Brejnrod A, Brislawn CJ, Brown CT, Callahan BJ, Caraballo-Rodríguez AM, Chase J, Cope EK, Da Silva R, Diener C, Dorrestein PC, Douglas GM, Durall DM, Duvallet C, Edwardson CF, Ernst M, Estaki M, Fouquier J, Gauglitz JM, Gibbons SM, Gibson DL, Gonzalez A, Gorlick K, Guo J, Hillmann B, Holmes S, Holste H, Huttenhower C, Huttley GA, Janssen S, Jarmusch AK, Jiang L, Kaehler BD, Kang KB, Keefe CR, Keim P, Kelley ST, Knights D, Koester I, Kosciolek T, Kreps J, Langille MGI, Lee J, Ley R, Liu YX, Loftfield E, Lozupone C, Maher M, Marotz C, Martin BD, McDonald D, McIver LJ, Melnik AV, Metcalf JL, Morgan SC, Morton JT, Naimey AT, Navas-Molina JA, Nothias LF, Orchanian SB, Pearson T, Peoples SL, Petras D, Preuss ML, Pruesse E, Rasmussen LB, Rivers A, Robeson MS 2nd, Rosenthal P, Segata N, Shaffer M, Shiffer A, Sinha R, Song SJ, Spear JR, Swafford AD, Thompson LR, Torres PJ, Trinh P, Tripathi A, Turnbaugh PJ, Ul-Hasan S, van der Hooft JJJ, Vargas F, Vázquez-Baeza Y, Vogtmann E, von Hippel M, Walters W, Wan Y, Wang M, Warren J, Weber KC, Williamson CHD, Willis AD, Xu ZZ, Zaneveld JR, Zhang Y, Zhu Q, Knight R, Caporaso JG. 2019. Reproducible, interactive, scalable and extensible microbiome data science using QIIME 2. Nature Biotechnology. 37: 852-857. DOI: 10.1038/s41587-019-0209-9.

Bray JR, Curtis JT. 1957. An ordination of upland forest communities of southern Wisconsin. Ecological Monographs. 27:325-349.

Brevik EC and Lazari AG. 2014. Rates of pedogenesis in reclaimed lands as compared to rates of natural pedogenesis. Soil Horizons. 55:1-6. DOI: 10.2136/sh13-06-0017 
494 Brown AM, Howe DK, Wasala SK, Peetz AB, Zasada IA, Denver DR. 2015. Comparative

495 Genomics of a plant-parasitic nematode endosymbiont suggest a role in nutritional symbiosis.

496 Genome Biology and Evolution. 7:2727-2746. DOI: 10.1093/gbe/evv176.

497 Callahan BJ, McMurdie PJ, Rosen MJ, Han AW, Johnson AJA, Holmes SP. 2016. DADA2:

498 High-resolution sample inference from Illumina amplicon data. Nature Methods. 13:581-583

499 DOI:10.1038/nmeth.3869

500 Campbell BJ, Polson SW, Hanson TE, Mack MC, Schuur EAG. 2010. The effect of nutrient

501 deposition on bacterial communities in Arctic tundra soil. Environmental Microbiology.

502 12:1842-1854. DOI:10.1111/j.1462-2920.2010.02189.x

503 Cerli C, Celi L, Kaiser K, Guggenberger G, Johansson MB, Cignetti A, Zanini E. 2008. Changes

504 in humic substances along an age sequence of Norway spruce stands planted on former

505 agricultural land. Organic Geochemistry. 39:1269-1280. DOI:

506 10.1016/j.orggeochem.2008.06.001

507 Chodak M, Gołębiewski M, Morawska-Płoskonka J, Kuduk K, Niklińska M. 2015. Soil chemical 508 properties affect the reaction of forest soil bacteria to drought and rewetting stress. Annals of

509 Microbiology. 65:1627-1637. DOI: 10.1007/s13213-014-1002-0

510 Dokuchaev VV. 1883. Russian Black Earth: Report to the Free Economic Society. St.

511 Petersburg: Declairon and Evdokimov.

512 Doula MK, Sarris A. 2016. Chapter 4 - Soil Environment. In: Poulopoulos SG, Inglezakis VJ, 513 eds. Environment and Development. Elsevier. 213-286. DOI: 10.1016/B978-0-444-62733-

514 9.00004-6.

515 Dragan NA. 2005. The soils cover evolution in the Crimea as result of ecodinamics processes.

516 Geopolitics and geodynamics of the regions. 1:59-71 (in russian)

517 Duan Y, Wu F, Wang W, He D, Gu JD, Feng H, Chen T, Liu G, An L. 2017. The microbial

518 community characteristics of ancient painted sculptures in Maijishan Grottoes, China. PLoS One.

519 12:e0179718. DOI: 10.1371/journal.pone.0179718.

520 Dubey A, Malla MA, Khan F, Chowdhary K, Yadav S, Kumar A, Sharma S, Khare PK, Khan M. 521 2019. Soil microbiome: a key player for conservation of soil health under changing climate.

522 Biodiversity and Conservation. 28:2405-2429 DOI: 10.1007/s10531-019-01760-5

523 Emmer IM. 1995. Humus form and soil development during a primary succession of

524 monoculture of Pinus sylvestris on poor sandy substrates. Ph.D. diss. University of Amsterdam.

525 Faith DP. 1992. Conservation evaluation and phylogenetic diversity. Biological Conservation.

526 61: 1-10. DOI: 10.1016/0006-3207(92)91201-3.

527 Fernandes CC, Kishi LT, Lopes EM, Omori WP, Souza JAM, Alves LMC, Lemos EGM. 2018.

528 Bacterial communities in mining soils and surrounding areas under regeneration process in a

529 former ore mine. Brazilian Journal of Microbiology. 49:489-502.

530 DOI:10.1016/j.bjm.2017.12.006

531 Fierer N, Bradford MA, Jackson RB. 2007. Toward an ecological classification of soil bacteria.

532 Ecology. 88:1354-1364. DOI:10.1890/05-1839 
533 Fierer N, Lauber CL, Ramirez KS, Zaneveld J, Bradford MA, Knight R. 2012. Comparative 534 metagenomic, phylogenetic and physiological analyses of soil microbial communities across 535 nitrogen gradients. The ISME Journal. 6:1007-17. DOI: 10.1038/ismej.2011.159.

536 Fox J, Monette G. 1992. Generalized collinearity diagnostics. Journal of the American Statistical 537 Association. 87:178-183. DOI: 10.1080/01621459.1992.10475190

538 Fox J. 1997. Applied Regression, Linear Models, and Related Methods. Sage Publications, Inc.

539 Frouz J. 2014. Soil Biota and Ecosystem Development in Post Mining Sites. DOI:

$540 \quad 10.1201 / \mathrm{b} 15502-17$.

541 Gagarina EI. 1996. Soils and soil cover of the plateu glacial elevations on the North - West of

542 Russian flat. Vestnik Sankt-Peterburgskogo Universiteta, Seriya Geologiya i Geografiya. 1:6254373.

544 Gagarina EI, Khantulev AA, Chikhikova NP. 1981. Genetic characteristics of soils on zvonets 545 clays. Soviet Soil Science. 13:1-9.

546 Gennadiev AN. 1990. Soils and time: models of development, Moscow, Izdatelstvo

547 MGU, 232 p. [in Russian]

548 Glaeser SP, Kämpfer P. 2014. The Family Sphingomonadaceae. In: Rosenberg E, DeLong EF, 549 Lory S, Stackebrandt E, Thompson F, eds. The Prokaryotes. Berlin, Heidelberg:Springer. 641550707.

551 Gladkov GV, Kimeklis AK, Zverev AO, Pershina EV, Ivanova EA, Kichko AA, Andronov EE, 552 Abakumov EV. 2019. Soil microbiome of the postmining areas in polar ecosystems in

553 surroundings of Nadym, Western Siberia, Russia. Open Agriculture. 4:684-696 DOI:

554 10.1515/opag-2019-0070

555 GOST 26107-84. 1984. Soils. Methods for determination of total nitrogen.

556 GOST 26205-91. 1991 Soils. Determination of mobile compounds of phosphorus and potassium 557 by Machigin method modified by CINAO.

558 GOST 26213-91. 1991. Soils. Methods for determination of organic matter.

559 Ho A, Ijaz UZ, Janssens TKS, Ruijs R, Kim SY, de Boer W, Termorshuizen A, van der Putten 560 WH, Bodelier PLE. 2017. Effects of bio-based residue amendments on greenhouse gas emission 561 from agricultural soil are stronger than effects of soil type with different microbial community 562 composition. GCB Bioenergy. 9:1707-1720. DOI: 10.1111/gcbb.12457

563 Homolák M, Kriaková E, Pichler V, Gömöryová E, Bebej J. 2017. Isolating the soil type effect 564 on the organic carbon content in a Rendzic Leptosol and an Andosol on a limestone plateau with 565 andesite protrusions. Geoderma. 302:1-5. DOI: 10.1016/j.geoderma.2017.04.009.

566 Huber KJ, Pascual J, Foesel BU, Overmann J. 2017. Blastocatellaceae. In Whitman WB, Rainey 567 F, Kämpfer P, Trujillo M, Chun J, DeVos P, Hedlund B, Dedysh S, eds. Bergey's Manual of 568 Systematics of Archaea and Bacteria. DOI:10.1002/9781118960608.fbm00290

569 Ivanova AA, Zhelezova AD, Chernov TI, Dedysh SN. 2020. Linking ecology and systematics of

570 acidobacteria: Distinct habitat preferences of the Acidobacteriia and Blastocatellia in tundra

571 soils. PLoS One. 15:e0230157. DOI: 10.1371/journal.pone.0230157 
572 Ivanova EA, Pershina EV, Shapkin VM, Kichko AA, Aksenova TS, Kimeklis AK, Gladkov GV, 573 Zverev AO, Vasilyeva NA, Andronov EE, Abakumov EV. 2020. Shifting prokaryotic

574 communities along a soil formation chronosequence and across soil horizons in a South Taiga

575 ecosystem. Pedobiologia. 150650. DOI: 10.1016/j.pedobi.2020.150650.

576 Janssen PH. 2006. Identifying the dominant soil bacterial taxa in libraries of 16S rRNA and 16S

577 rRNA genes. Applied and Environmental Microbiology. 72:1719-1728. DOI:

578 10.1128/AEM.72.3.1719-1728.2006

579 Janssen S, McDonald D, Gonzalez A, Navas-Molina JA, Jiang L, Xu ZZ, Winker K, Kado DM, 580 Orwoll E, Manary M, Mirarab S, Knight R. 2018. Phylogenetic placement of exact amplicon 581 sequences improves associations with clinical information. mSystems. 3:e0021-18. DOI:

$582 \quad 10.1128 / \mathrm{mSystems} .00021-18$

583 Jones RT, Robeson MS, Lauber CL, Hamady M, Knight R, Fierer N. 2009. A comprehensive 584 survey of soil acidobacterial diversity using pyrosequencing and clone library analyses. The 585 ISME journal. 3:442-453. DOI: 10.1038/ismej.2008.127

586 Kappler U, Nouwens AS. 2013. Metabolic adaptation and trophic strategies of soil bacteria-C1587 metabolism and sulfur chemolithotrophy in Starkeya novella. Frontiers in Microbiology. 17:304. 588 DOI: $10.3389 /$ fmicb.2013.00304.

589 Kassambara A. 2019. ggpubr: 'ggplot2' Based Publication Ready Plots. R package version 0.2.3. 590 Available at https://CRAN.R-project.org/package=ggpubr (accessed 10 May 2020)

591 Kembel SW, Cowan PD, Helmus MR, Cornwell WK, Morlon H, Ackerly DD, Blomberg SP, 592 Webb CO. 2010. Picante: R tools for integrating phylogenies and ecology. Bioinformatics.

593 26:1463-1464. DOI: 10.1093/bioinformatics/btq166

594 Kielak AM, Barreto CC, Kowalchuk GA, van Veen JA, Kuramae EE. 2016. The ecology of 595 Acidobacteria: moving beyond genes and genomes. Frontiers in Microbiology. 7:744.

596 DOI:10.3389/fmicb.2016.00744

597 Kimble JC, Winter AS, Spilde MN, Sinsabaugh RL, Northup DE. 2018. A potential central role 598 of Thaumarchaeota in N-Cycling in a semi-arid environment, Fort Stanton Cave, Snowy River 599 passage, New Mexico, USA. FEMS Microbiology Ecology. 94:fiy173.

600 DOI:10.1093/femsec/fiy173.

601 Kimeklis AK, Dmitrakova YA, Pershina EV, Ivanova EA, Zverev AO, Gladkov GV, Kichko 602 AA, Andronov EE, Abakumov EV. 2020. Analysis of microbiome of recultivated soils of the 603 kingisepp area of phosphorite mining. Sel'skokhozyaistvennaya Biologiya [Agricultural Biology]. 604 55:137-152. DOI: 10.15389/agrobiology.2020.1.137eng

605 Kruskal JB. 1964. Multidimensional scaling by optimizing goodness-of-fit to a nonmetric 606 hypothesis. Psychometrika. 29:1-28.

607 Lazarevic V, Gaia N, Girard M, Francois P, Schrenzel J. 2013. Comparison of DNA extraction 608 methods in analysis of salivary bacterial communities. PLoS One. 8:67699, DOI:

609 101371/journal.pone.0067699. 
610 Lewin GR, Carlos C, Chevrette MG, Horn HA, McDonald BR, Stankey RJ, Fox BG, Currie CR. 611 2016. Evolution and ecology of Actinobacteria and their bioenergy applications. Annual Review 612 of Microbiology. 8:235-254. DOI: 10.1146/annurev-micro-102215-095748.

613 Lisetskii FN, Ergina EI. 2010. Soil development on the Crimean Peninsula in the Late Holocene.

614 Eurasian Soil Science. 43:601-613. DOI: 10.1134/S1064229310060013

615 Love MI, Huber W, Anders S. 2014. Moderated estimation of fold change and dispersion for

616 RNA-seq data with DESeq2. Genome Biology. 15:550. DOI: 10.1186/s13059-014-0550-8

617 Lozupone C, Knight R. 2005. UniFrac: a new phylogenetic method for comparing microbial

618 communities. Applied and Environmental Microbiology. 71: 8228-8235. DOI:

619 10.1128/AEM.71.12.8228-8235.2005.

620 Mann HB, Whitney DR. 1947. On a test of whether one of two random variables is stochastically 621 larger than the other. The Annals of Mathematical Statistics. 18: 50-60.

622 McCune B. 1997. Influence of noisy environmental data on canonical correspondence analysis.

623 Ecology. 78:2617-2623. DOI: 10.1890/0012-9658(1997)078[2617:IONEDO]2.0.CO;2

624 McMurdie PJ, Holmes S. 2013. phyloseq: An R package for reproducible interactive analysis

625 and graphics of microbiome census data. PLoS ONE. 8:e61217. DOI:

626 10.1371/journal.pone.006121

627 Mokma DL, Yli-Halla M, Lindqvist K. 2004. Podzol formation in sandy soils of Finland.

628 Geoderma. 120:259-272. DOI: 10.1016/j.geoderma.2003.09.008

629 Morrissey EM, Mau RL, Schwartz E, Caporaso JG, Dijkstra P, van Gestel N, Koch BJ, Liu CM, 630 Hayer M, McHugh TA, Marks JC, Price LB, Hungate BA. 2016. Phylogenetic organization of 631 bacterial activity. The ISME Journal. 10:2336-2340. DOI: 10.1038/ismej.2016.28.

632 Narendrula-Kotha R, Nkongolo KK. 2017. Microbial response to soil liming of damaged 633 ecosystems revealed by pyrosequencing and phospholipid fatty acid analyses. PLoS One. 634 12:e0168497. DOI: 10.1371/journal.pone.0168497.

635 Nearing JT, Douglas GM, Comeau AM, Langille, MGI. 2018. Denoising the Denoisers: An 636 independent evaluation of microbiome sequence error- correction approaches. PeerJ. 6:e5364.

637 DOI: 10.7717/peerj.5364.

638 Nelkner J, Henke C, Lin TW, Pätzold W, Hassa J, Jaenicke S, Grosch R, Pühler A, Sczyrba A, 639 Schlüter A. 2019. Effect of long-term farming practices on agricultural soil microbiome 640 members represented by metagenomically assembled genomes (MAGs) and their predicted 641 plant-beneficial genes. Genes. 10: 424. DOI: 10.3390/genes10060424.

642 Oberhofer M, Hess J, Leutgeb M, Gössnitzer F, Rattei T, Wawrosch C, Zotchev SB. 2019.

643 Exploring Actinobacteria associated with rhizosphere and endosphere of the native alpine 644 medicinal plant Leontopodium nivale subspecies alpinum. Frontiers in Microbiology. 10:2531. 645 DOI: $10.3389 /$ fmicb.2019.02531

646 Oksanen J, Blanchet FG, Friendly M, Kindt R, Legendre P, McGlinn D, Minchin PR, O'Hara 647 RB, Simpson GL, Solymos P, Stevens MHH, Szoecs E, Wagner H. 2019. vegan: Community 648 Ecology Package. R package version 2.5-6. Available at https://CRAN.R-

649 project.org/package $=$ vegan $($ accessed 10 May 2020) 
650 Oren A. 2014. The Family Xanthobacteraceae. In: Rosenberg E, DeLong EF, Lory S,

651 Stackebrandt E, Thompson F, eds. The Prokaryotes. Berlin, Heidelberg:Springer.

652 Palmer MW. 1993. Putting things in even better order: The advantages of canonical

653 correspondence analysis. Ecology. 74:2215-2230.

654 Pedersen TL. 2019. ggforce: Accelerating 'ggplot2'. R package version 0.3.1. Available at

655 https://CRAN.R-project.org/package=ggforce (accessed 10 May 2020)

656 Perkins SO. 1951. Soil Survey of Cherokee County, North Carolina. U.S. Government Printing

657 Office. 95

658 Pester M, Schleper C, Wagner M. 2011. The Thaumarchaeota: an emerging view of their

659 phylogeny and ecophysiology. Current Opinion in Microbiology. 14:300-306. DOI:

660 10.1016/j.mib.2011.04.007

661 Quast C, Pruesse E, Yilmaz P, Gerken J, Schweer T, Yarza P, Peplies J, Glöckner FO. 2013. The

662 SILVA ribosomal RNA gene database project: improved data processing and web-based tools.

663 Nucleic Acids Research. 41:D590-D596. DOI: 10.1093/nar/gks1219.

664 R Core Team. 2018. R: A language and environment for statistical computing. Austria: $\mathrm{R}$

665 Foundation for Statistical Computing, Vienna. Available at https:/www.R-project.org/.

666 (accessed 10 May 2020)

667 Ramirez KS, Lauber CL, Knight R, Bradford MA, Fierer N. 2010. Consistent effects of nitrogen

668 fertilization on soil bacterial communities in contrasting systems. Ecology. 91:3463-3470. DOI:

$66910.1890 / 10-0426.1$

670 RStudio Team. 2016. RStudio: Integrated Development for R. Boston, MA: RStudio, Inc.

671 Available at http://www.rstudio.com/ (accessed 10 May 2020)

672 Saleem M, Hu J, Jousset A. 2019. More than the sum of its parts: microbiome biodiversity as a

673 driver of plant growth and soil health. Annual Review of Ecology, Evolution, and Systematics.

674 50:145-168. DOI: 10.1146/annurev-ecolsys-110617-062605

675 Schabereiter-Gurtner C, Pinar G, Vybiral D, Lubitz W, Rölleke S. 2001. Rubrobacter-related

676 bacteria associated with rosy discoloration of masonry and lime wall paintings. Archives of

677 microbiology. 176:347-54. DOI: 10.1007/s002030100333.

678 Shannon CE, Weaver W. 1949. The mathematical theory of communication. Urbana: University

679 of Illinois Press.

680 Simpson E. 1949. Measurement of Diversity. Nature. 163:688. DOI: 10.1038/163688a0

681 Sokolov DA, Androkhanov VA, Kulizhskii SP Gurkova EA, Loiko SV. 2015. Morphogenetic

682 diagnostics of soil formation on tailing dumps of coal quarries in Siberia. Eurasian Soil Science.

683 48:95-105. DOI: 10.1134/S1064229315010159.

684 SRA Toolkit Development Team. Available at http://ncbi.github.io/sra-tools/ (accessed 10 July

685 2020)

686 Stolba V, Lisetskii FN \& Marinina O. 2015. Indicators of agricultural soil genesis under varying

687 conditions of land use, Steppe Crimea. Geoderma. 239-240:304-316. DOI:

688 10.1016/j.geoderma.2014.11.006. 
689 Targulian VO, Krasilnikov PV. 2007. Soil system and pedogenic processes: Self-organization, 690 time scales, and environmental significance. CATENA. 71:373-381. DOI:

691 10.1016/j.catena.2007.03.007.

692 Targulian, VO, Bronnikova MA. 2019. Soil Memory: Theoretical Basics of the Concept, Its

693 Current State, and Prospects for Development. Eurasian Soil Science. 52:229-243. DOI:

694 10.1134/S1064229319030116

695 Taş N, Prestat E, Wang S, Wu Y, Ulrich C, Kneafsey T, Tringe SG, Torn MS, Hubbard SS, 696 Jansson JK. 2018. Landscape topography structures the soil microbiome in arctic polygonal 697 tundra. Nature Communications. 9:777. DOI: 10.1038/s41467-018-03089-z.

698 ter Braak CJF. 1986. Canonical Correspondence Analysis: a new eigenvector technique for 699 multivariate direct gradient analysis. Ecology. 67:1167-1179. DOI: 10.2307/1938672

700 Toyota K. Bacillus-related spore formers: attractive agents for plant growth promotion. 2015. 701 Microbes and Environments. 30:205-207. DOI: 10.1264/jsme2.me3003rh.

702 Wang Q, Garrity, G, Tiedje J, Cole JR. 2007. Naïve Bayesian classifier for rapid assignment of 703 rRNA sequences into the new bacterial taxonomy. Applied and Environment Microbiology.

704 73:5261-5267. DOI: 10.1128/AEM.00062-07

705 Wei Z, Gu Y, Friman VP, Kowalchuk GA, Xu Y, Shen Q, Jousset A. 2019. Initial soil

706 microbiome composition and functioning predetermine future plant health. Science Advances.

707 5:eaaw0759. DOI: 10.1126/sciadv.aaw0759.

708 Wickham H, Averick M, Bryan J, Chang W, McGowan L, François R, Grolemund G, Hayes A, 709 Lionel H, Hester J, Kuhn M, Pedersen T, Miller E, Bache S, Müller K, Ooms J, Robinson D,

710 Seidel D, Spinu V, Yutani H. 2019. Welcome to the tidyverse. Journal of Open Source Software.

711 4: 1686. DOI: $10.21105 /$ joss.01686

712 Wüst PK, Foesel BU, Geppert A, Huber KJ, Luckner M, Wanner G, Overmann J. 2016.

713 Brevitalea aridisoli, B. deliciosa and Arenimicrobium luteum, three novel species of

714 Acidobacteria subdivision 4 (class Blastocatellia) isolated from savanna soil and description of

715 the novel family Pyrinomonadaceae. International Journal of Systematic and Evolutionary

716 Microbiology. 66:3355-3366. DOI:10.1099/ijsem.0.001199

717 Yu G, Tsan-Yuk Lam T, Zhu H, Guan Y. 2018. Two methods for mapping and visualizing

718 associated data on phylogeny using ggtree. Molecular Biology and Evolution. 35:3041-3043.

719 DOI: $10.1093 / \mathrm{molbev} / \mathrm{msy} 194$

720 Zhou X, Fornara D, Ikenaga M, Akagi I, Zhang R, Jia Z. 2016. The resilience of microbial 721 community under drying and rewetting cycles of three forest soils. Frontiers in Microbiology.

722 7:1101. DOI: 10.3389/fmicb.2016.01101 
Figure 1

Map of the Crimean Peninsula and the location of sampling sites. Modified after Soil Regions Map of the European Union and Adjacent Countries (BGR, 2005).

Colour and numbers 1-4 mark different soil types. Sampling sites are marked with red circles.

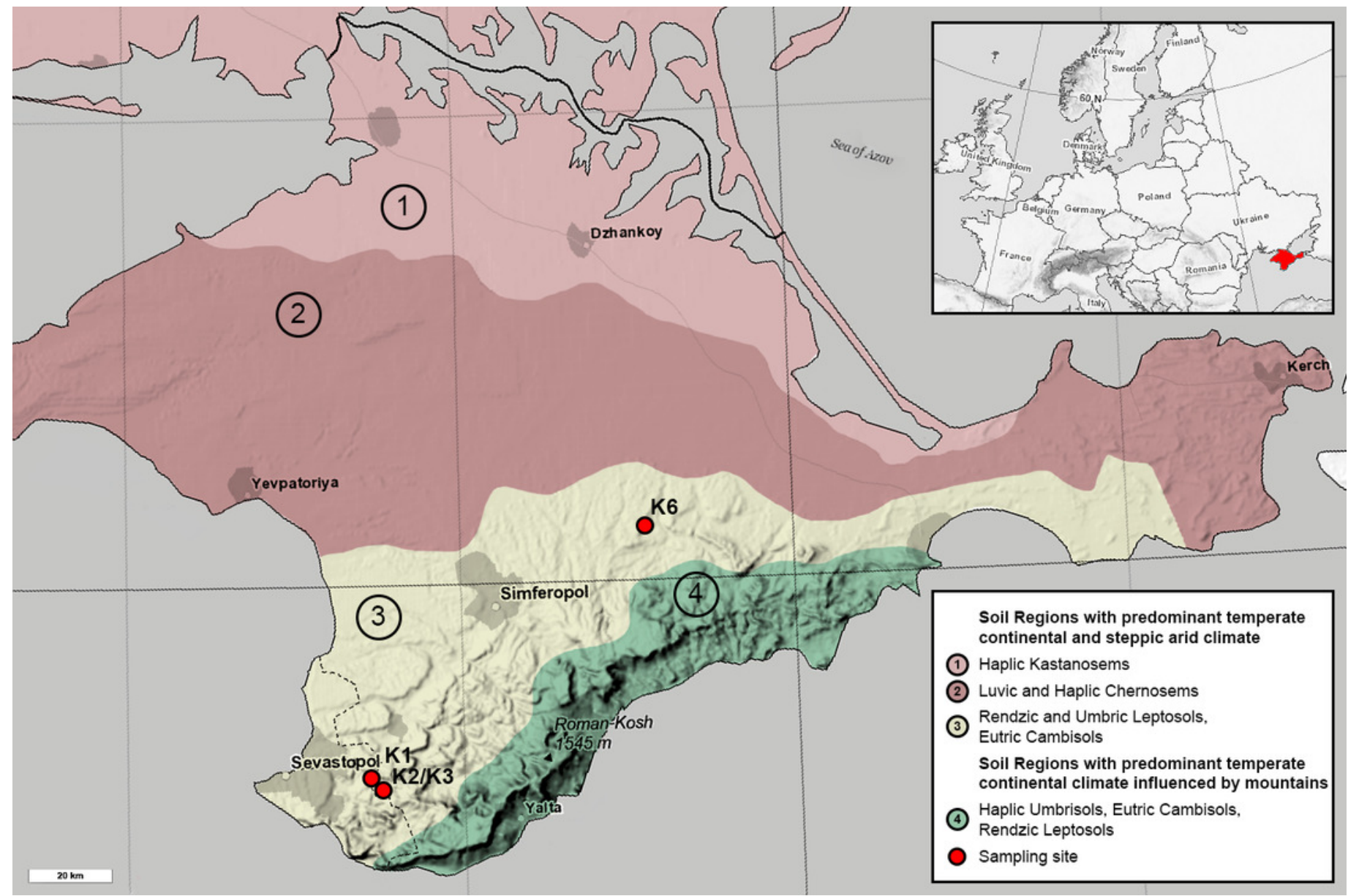


Figure 2

Abundance of bacteria and archaea in all samples assessed by qPCR.

Values are given as the common logarithm of the means of ribosomal operon number per $1 \mathrm{~g}$ soil $(n=15)$. Significance is given as a standard error of means.

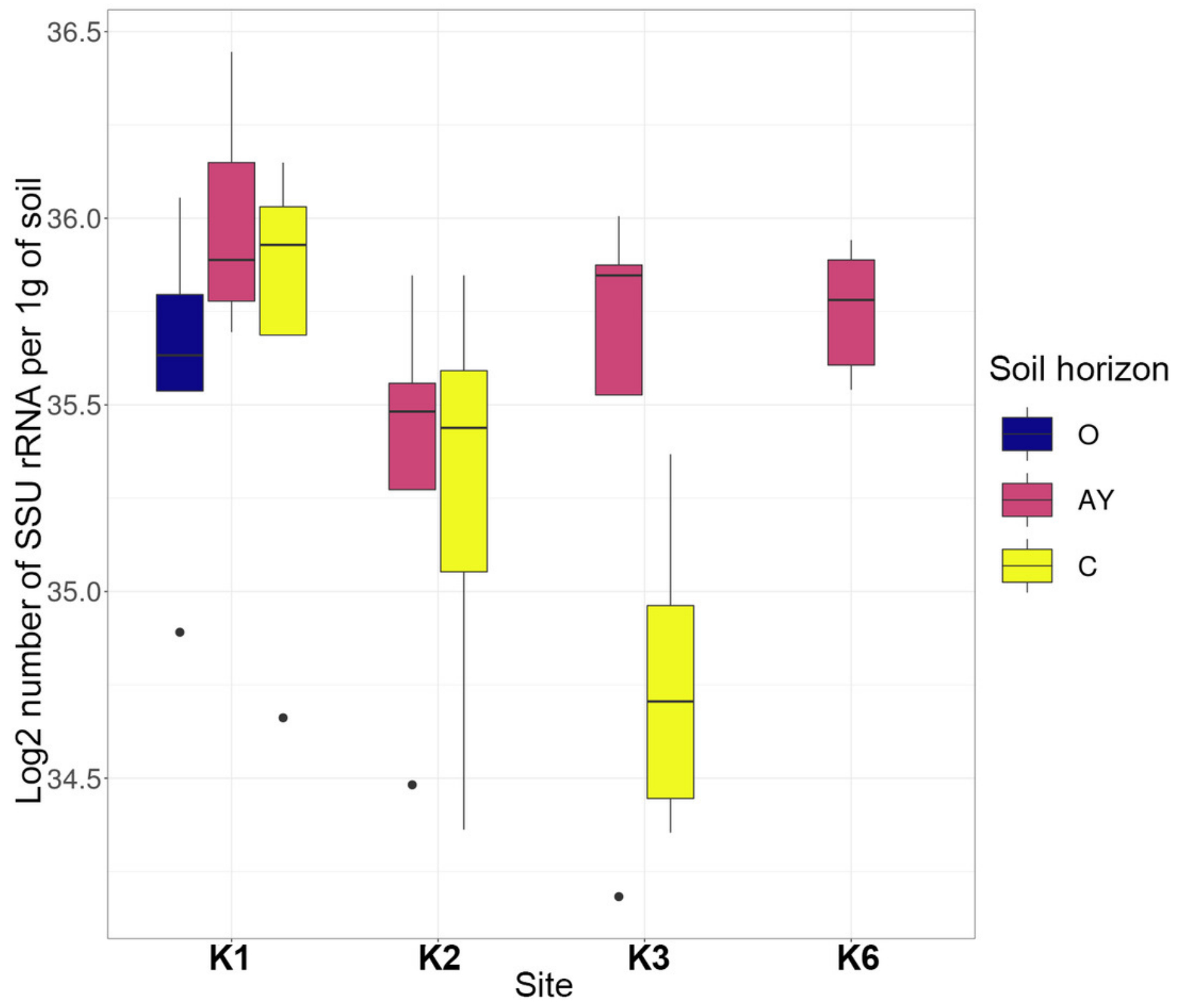




\section{Figure 3}

Heatmap for the 20 most abundant phyla across all samples.

Orange stands for more abundant, and blue for less abundant.

\begin{tabular}{|c|c|c|c|c|c|c|c|c|}
\hline Actinobacteria - & 28.6 & 31.5 & 26.5 & 25.3 & 22.8 & 21.7 & 22.5 & 18.4 \\
\hline Proteobacteria - & 38.8 & 30.3 & 26.2 & 20.3 & 16.9 & 22.1 & 15.8 & 23.2 \\
\hline Acidobacteria - & 7 & 10.5 & 12.4 & 12 & 12.5 & 10.1 & 13.5 & 12 \\
\hline Bacteroidetes - & 8.6 & 4.4 & 2.6 & 14.7 & 9.2 & 14 & 6.4 & 13 \\
\hline Thaumarchaeota - & 1.3 & 3.7 & 8.9 & 5.5 & 10.9 & 4 & 7.9 & 7.3 \\
\hline Planctomycetes - & 5.6 & 7.2 & 6.5 & 5.7 & 3.5 & 5 & 5.5 & 4.8 \\
\hline Verrucomicrobia - & 3.1 & 3.7 & 5.1 & 4.2 & 4.9 & 5.1 & 9.5 & 3.7 \\
\hline Firmicutes - & 0.1 & 0.2 & 0.8 & 2.6 & 8.1 & 5.7 & 7.5 & 5.9 \\
\hline Chloroflexi- & 2.5 & 2.8 & 2.6 & 1.8 & 1.7 & 2.3 & 1.4 & 3.1 \\
\hline Gemmatimonadetes - & 1.1 & 1.4 & 1.6 & 1 & 1.3 & 1.3 & 1.1 & 1.6 \\
\hline Entotheonellaeota - & 0.1 & 0.5 & 1.2 & 1.4 & 1.3 & 0.6 & 1.2 & 0.7 \\
\hline Cyanobacteria- & 0.2 & 0.2 & 0.2 & 0.9 & 0.3 & 3.3 & 0.3 & 0.8 \\
\hline Patescibacteria - & 0.9 & 0.7 & 0.6 & 0.5 & 0.8 & 0.5 & 0.8 & 1.5 \\
\hline Rokubacteria - & 0.2 & 0.9 & 1.8 & 0.1 & 0.4 & 0.1 & 0.5 & 0.2 \\
\hline k_Bacteria_Seq9 & 0 & 0 & 0.1 & 0.4 & 1.3 & 0.4 & 1.8 & 0.2 \\
\hline Nitrospirae- & 0.1 & 0.2 & 0.3 & 0.2 & 0.2 & 0.1 & 0.1 & 0.6 \\
\hline Armatimonadetes - & 0.2 & 0.1 & 0.1 & 0.2 & 0.1 & 0.2 & 0.1 & 0.2 \\
\hline FBP- & 0.1 & 0 & 0 & 0.5 & 0.1 & 0.3 & 0.1 & 0.1 \\
\hline k__Unclassified_Seq74- & 0 & 0 & 0 & 0.1 & 0.5 & 0.1 & 0.6 & 0 \\
\hline \multirow[t]{2}{*}{ Elusimicrobia } & 0.1 & 0.1 & 0.1 & 0.1 & 0.1 & 0.1 & 0 & 0.2 \\
\hline & $\mathrm{K} 1-\mathrm{O}$ & $\mathrm{K} 1-\mathrm{AY}$ & $\mathrm{K} 1-\mathrm{AC}$ & $\mathrm{K} 2-\mathrm{AY}$ & $\mathrm{K} 2-\mathrm{C}$ & K3-AY & K3-C & K6-AY \\
\hline
\end{tabular}


Figure 4

Alpha diversity indexes for each soil horizon.

(A) Observed, (B) PD, (C) Shannon, (D) inverted Simpson. Data presented by violin and box plots, which show the kernel probability density of the data at different sample values. Pvalues are given above plots.
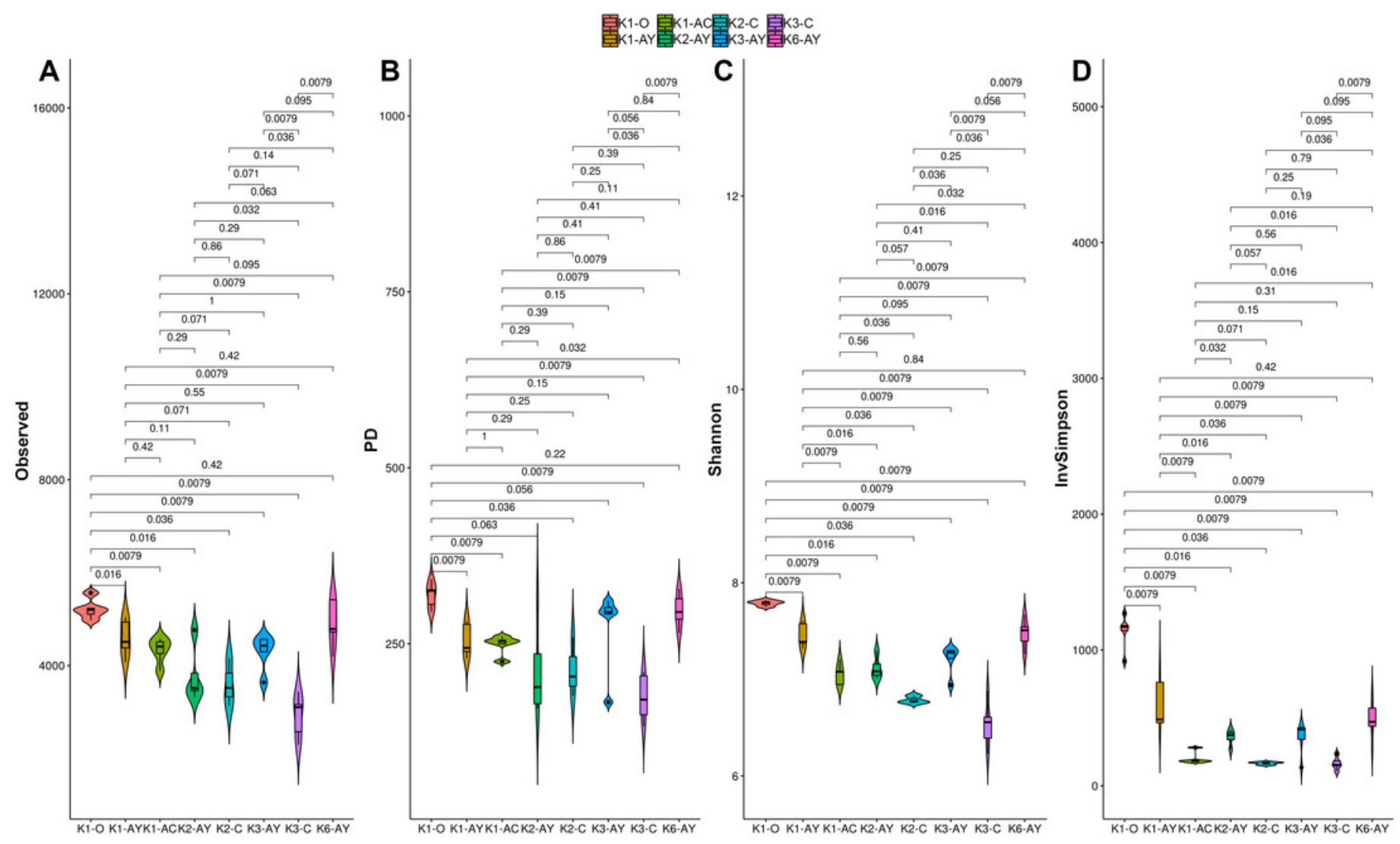
Figure 5

NMDS plots of Beta diversity.

(A) Bray-Curtis distance matrix. (B) UniFrac. (C) weighted UniFrac. Sample repeats are surrounded by ellipses, estimated using the Khachiyan algorithm.
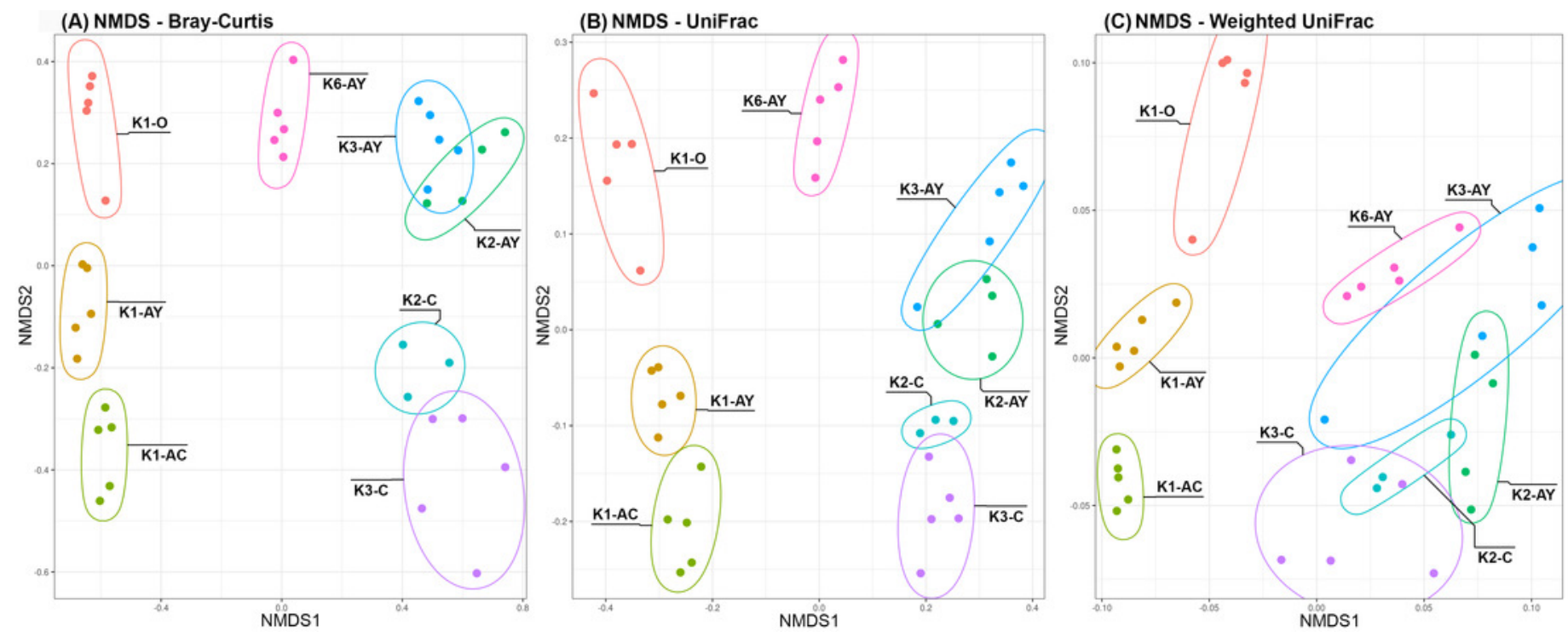
Figure 6

CCA

Direction of the vectors shows the degree of covariation between factors.

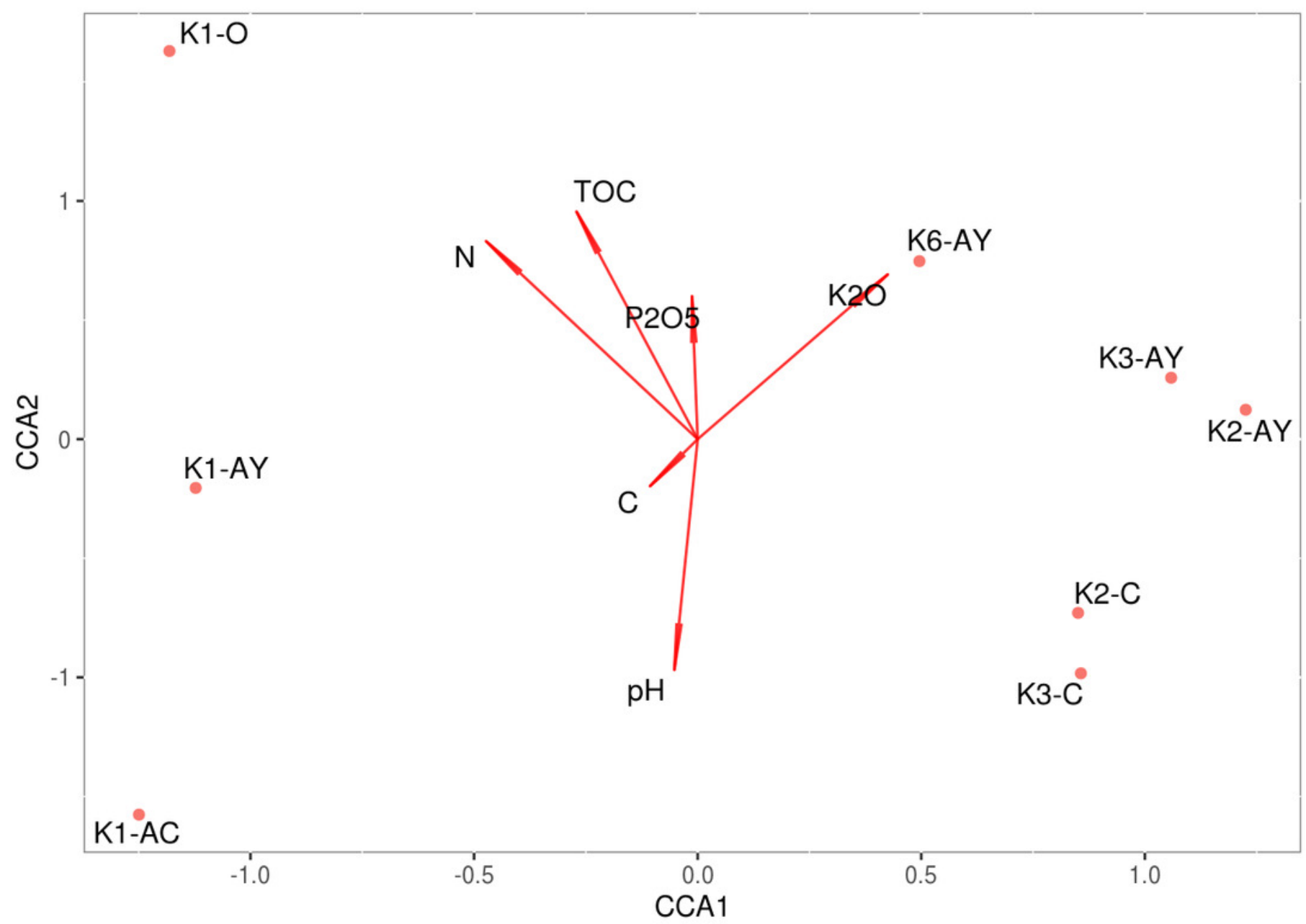




\section{Figure 7}

Phylogenetic tree with phylotypes, which abundance shifts significantly (padj < 0.05 ) between $\mathrm{K} 1$ and $\mathrm{K} 3$ sites.

Shifts are presented as log2foldchange values. The left column shows shifts in the AY horizon, right column, the $\mathrm{AC} / \mathrm{C}$ horizon. Red indicates an increase in $\mathrm{K} 3$, blue, in $\mathrm{K} 1$. 


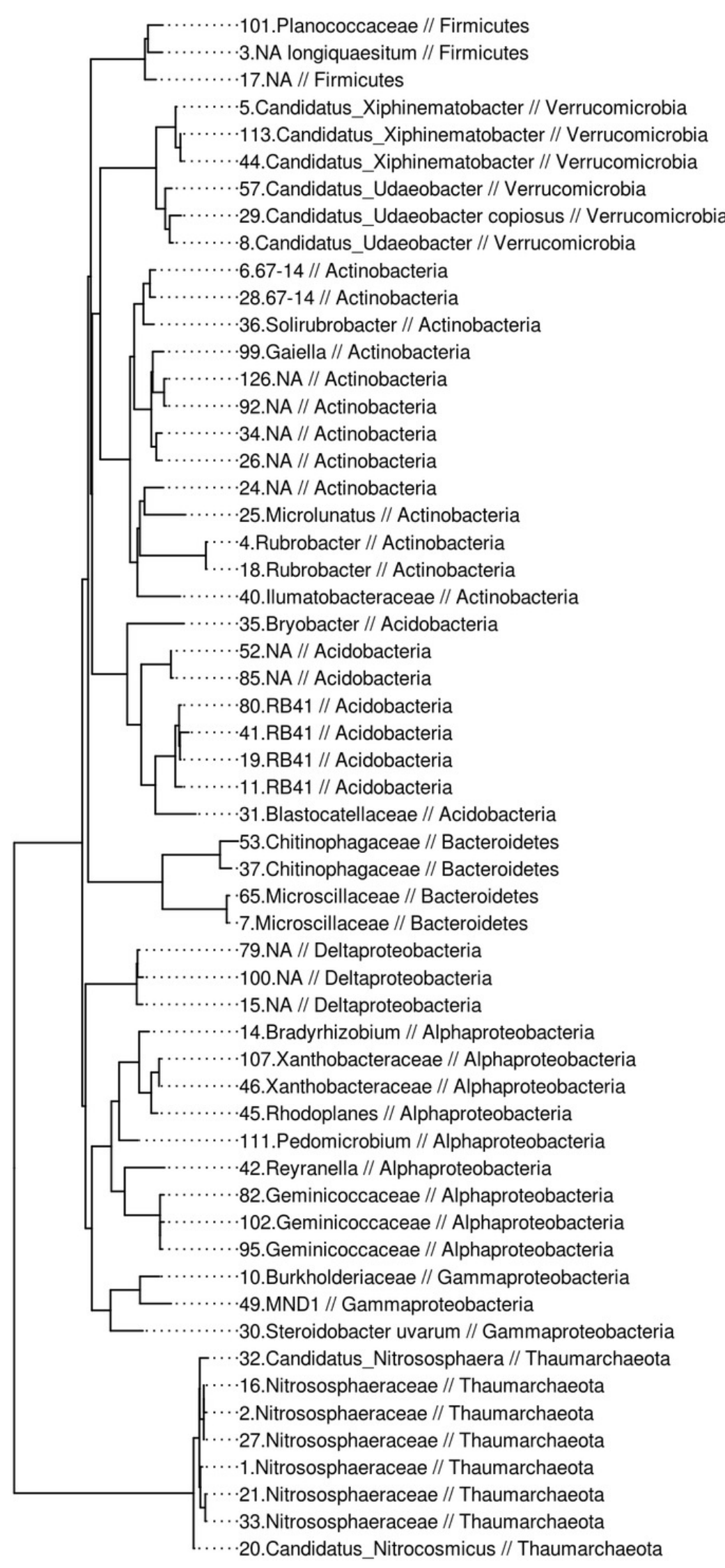

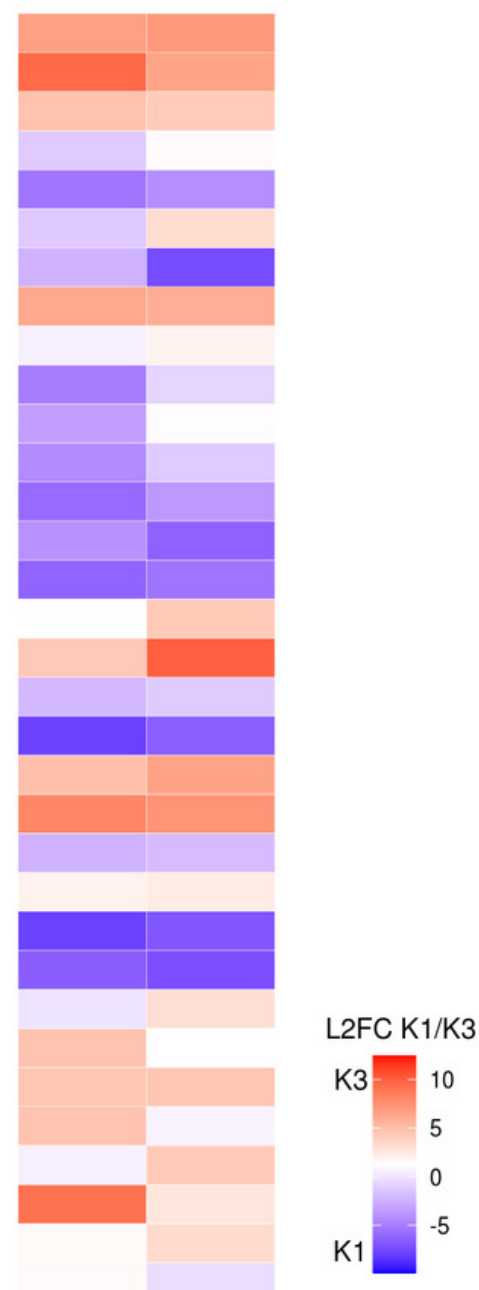

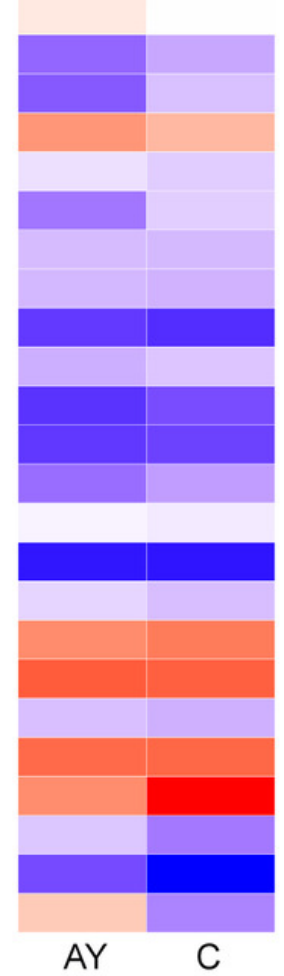


Table $\mathbf{1}$ (on next page)

Main soil chemical parameters 


\begin{tabular}{lllllllll}
\hline Site & Description & Horizon & $\begin{array}{l}\mathrm{P}_{2} \mathrm{O}_{5} \\
(\mathrm{mg} / \mathrm{kg})\end{array}$ & $\begin{array}{l}\mathrm{K}_{2} \mathrm{O} \\
(\mathrm{mg} / \mathrm{kg})\end{array}$ & $\mathrm{pH}$ & $\mathrm{TOC}(\%)$ & $\begin{array}{l}\mathrm{C}_{\text {carb }} \\
(\%)\end{array}$ & $\begin{array}{l}\mathrm{N}_{\text {tot }} \\
(\%)\end{array}$ \\
\hline $\mathrm{K} 1$ & Eski-Kermen. & $\mathrm{O}$ & 123 & 515 & 7.6 & $>22.95$ & 20.24 & 1.47 \\
& 700 years & $\mathrm{AY}$ & 12 & 212 & 8.0 & 7.32 & 34.50 & 0.78 \\
& & $\mathrm{C}$ & 6 & 45 & 8.2 & 0.23 & 33.12 & 0.03 \\
$\mathrm{~K} 2$ & Holmovka. & $\mathrm{AY}$ & 8 & 595 & 7.9 & 6.84 & 34.13 & 0.10 \\
& 75 years & $\mathrm{C}$ & 2 & 14 & 8.2 & 0.47 & 45.60 & 0.43 \\
$\mathrm{~K} 3$ & Holmovka. & $\mathrm{AY}$ & 11 & 820 & 7.8 & 8.88 & 28.57 & 0.48 \\
& Benchmark soil & $\mathrm{C}$ & 5 & 56 & 8.1 & 0.67 & 4.80 & 0.05 \\
$\mathrm{~K} 6$ & Leptosol. 50 years & $\mathrm{AY}$ & 285 & 1110 & 7.7 & 11.70 & 23.81 & 0.58 \\
\hline
\end{tabular}


Table 2 (on next page)

Coefficient of determination $\left(R^{2}\right)$ for each soil factor assessed by PERMANOVA 


\begin{tabular}{lll}
\hline Factor & $\mathrm{R}^{2}$ & $\operatorname{Pr}(>\mathrm{F})$ \\
\hline Horizon & 0.52179978 & 0.001 \\
Site & 0.49421618 & 0.001 \\
$\mathrm{~N}_{\text {tot }}$ & 0.18573955 & 0.001 \\
$\mathrm{TOC}$ & 0.17705733 & 0.001 \\
$\mathrm{pH}$ & 0.15795176 & 0.001 \\
$\mathrm{~K}_{2} \mathrm{O}$ & 0.14989736 & 0.001 \\
$\mathrm{P}_{2} \mathrm{O}_{5}$ & 0.11987081 & 0.002 \\
$\mathrm{C}_{\text {carb }}$ & 0.04737008 & 0.100 \\
\hline
\end{tabular}

1 